\title{
COMMENTARY
}

\section{Over-distension of the airways by mechanical ventilation in the elderly: adding insult to injury}

\author{
Aurora Pop-Vicas* and Steven M Opal \\ See related research by Setzer et al., http://ccforum.com/content/17/3/R99
}

\begin{abstract}
Setzer and colleagues demonstrate that older animals are more susceptible to ventilator-induced lung injury than young animals and develop a more pronounced local and systemic cytokine response to high tidal volumes. These data have significant implications for older patients receiving mechanical ventilation if these findings can be translated to human critical care medicine.
\end{abstract}

In the previous issue of Critical Care, Setzer and colleagues [1] describe an interesting set of experiments in which ventilation with large tidal volumes is associated with enhanced inflammatory changes and excess mortality in elderly rats compared to their younger counterparts. It is now well established that over-distention of the alveoli can damage alveolar lining cells and result in local and systemic inflammatory immune responses that can be deleterious to the host, even in the absence of pulmonary infection [2]. This problem, known as ventilator-induced lung injury (VILI), is a major, yet avoidable, complication of mechanical ventilation. Low tidal volume ventilatory strategies have now become the standard of care given the findings of the ARDSnet trial [3] and other supporting studies [4] and are now part of the Surviving Sepsis Campaign guidelines to limit ventilator-associated lung injury [5].

In the United States, elderly people (aged $>65$ years) comprised $12.4 \%$ of the population in the year 2000 , with an expected growth to $19 \%$ by the year 2030 [6]. Similar population changes are expected in many countries over the next several decades. Pneumonia remains a major source of morbidity in seniors, and the incidence of disease rises steadily with advanced age [7]. In 2011, the incidence of hospitalization for pneumonia, chronic

*Correspondence: Aurora_Pop-Vicas@brown.edu

ID Division, Memorial Hospital of RI, 111 Brewster Street, Pawtucket, RI 02860, USA obstructive pulmonary disease, and sepsis among people aged $>65$ years in the US was just over 1.5 million/year [8] with a substantial number of these patients needing ventilatory support. The work of Setzer and colleagues indicates that elderly mammals (rats in their study) are more susceptible to VILI than younger animals. It is logical to assume that this excess risk of VILI in older mammals extends to Homo sapiens. If this is indeed the case, great care should be taken to avoid this preventable complication in older patients receiving mechanical ventilation.

Elderly patients are already known to be more vulnerable to infection due to the development of immune-senescence - a specific process characterized by a rather profound set of defects in immune function observed with aging [9]. B lymphocyte responses are markedly blunted and manifest by poor vaccine response rates and susceptibility to encapsulated bacterial pathogens $[10,11]$. Cell-mediated immune function with both CD4 and CD8 cells are markedly impaired with advanced age and explain the increased susceptibility of older patients to tuberculosis, listeria infections, viral pathogens and a number of intracellular microbial pathogens [12]. While the adaptive immune response is characterized by gradual depression over time, the same situation is not observed with innate immune responses. Innate immune responses are either maintained or even enhanced in the elderly. Older patients are less capable of rapid resolution of inflammatory responses. Patients aged over 60 years exposed to standard endotoxin challenge develop more pronounced and prolonged reductions in mean arterial blood pressure compared to younger volunteers and have a greater likelihood of fever and tumor necrosis factor elevation $[9,13]$.

Based upon these age-related immune dysfunctions, it is perhaps not surprising that older rats had more pronounced immunologic injury compared to younger animals. It is reasonable to expect that the same will be true in elderly patients on mechanical ventilators versus younger patients. All of this has yet to be clearly demonstrated. The study has at least two important implications for critical care specialists and researchers. 
First, use extra care in choosing lung-protective strategies for older, mechanically ventilated patients in the intensive care unit. A search of existing data bases or future prospective studies should be undertaken to determine the degree to which age plays a part in susceptibility to VILI. The second implication is also an important one: we should study old animals in preclinical studies in sepsis, acute lung injury in general and VILI in particular. These pathologic processes are primarily seen in the elderly. In the animal research laboratory, young, healthy animals are the traditional experimental subjects for pneumonia, sepsis and lung injury studies. We know that the immune response of elderly animals and humans clearly differs from younger animals and patients. We have enough trouble extrapolating animal data to human pathophysiology without further confusing the issue by studying young animals and comparing them with old adult patients [14].

Older animals are usually not studied because of the expense and extra animal husbandry to maintain animals until they have aged (approximately 2 to 3 years for mice and rats). Data from this study and other studies in elderly experimental animals suggest that it may be worth the wait, and provide greater information than the standard experimental models using young, healthy animals $[1,9]$. The investigators are to be congratulated for making this point in their experimental study, and hopefully this will stimulate other groups to use older animals in their experimental protocols.

\section{Abbreviations}

VILI, ventilator-induced lung injury.

\section{Author details}

${ }^{1}$ ID Division, Memorial Hospital of RI, 111 Brewster Street, Pawtucket, RI 02860, USA. ${ }^{2}$ Infectious Disease Division, The Alpert Medical School of Brown

University, Providence, RI 02903-4228, USA.

Published: 4 July 2013

\section{References}

1. Setzer F, Oschatz K, Hueter L, Schmidt B, Schwarzkopf K, Schreiber T: Susceptibility to ventilator induced lung injury is increased in senescent rats. Crit Care 2013, 17:R99.

2. International consensus conferences in intensive care medicine:
Ventilator-associated Lung Injury in ARDS. This official conference report was cosponsored by the American Thoracic Society, The European Society of Intensive Care Medicine, and The Societe de Reanimation de Langue Francaise, and was approved by the ATS Board of Directors, July 1999. Am J Respir Crit Care Med 1999, 160:2118-2124.

3. Ventilation with lower tidal volumes as compared with traditional tidal volumes for acute lung injury and the acute respiratory distress syndrome. The Acute Respiratory Distress Syndrome Network. N Eng/ J Med 2000, 342:1301-1308.

4. Petrucci N, De Feo C: Lung protective ventilation strategy for the acute respiratory distress syndrome. Cochrane Database Syst Rev 2013, 2:CD003844

5. Dellinger RP, Levy MM, Rhodes A, Annane D, Gerlach H, Opal SM, Sevransky JE, Sprung CL, Douglas IS, Jaeschke R, Osborn TM, Nunnally ME, Townsend SR, Reinhart K, Kleinpell RM, Angus DC, Deutschman CS, Machado FR, Rubenfeld GD, Webb S, Beale RJ, Vincent JL, Moreno R; Surviving Sepsis Campaign Guidelines Committee including The Pediatric Subgroup: Surviving Sepsis Campaign: international guidelines for management of severe sepsis and septic shock, 2012. Intensive Care Med 2013, 39:165-228.

6. Department of Health \& Human Services: Aging Statistics [http://www.aoa.gov/Aging_Statistics/]

7. Jackson ML, Neuzil KM, Thompson WW, Shay DK, Yu O, Hanson CA, Jackson LA: The burden of community-acquired pneumonia in seniors: results of a population-based study. Clin Infect Dis 2004, 39:1642-1650.

8. National Center for Health Statistics: Health, United States. 2011:335-336 [http://www.cdc.gov/NCHS/data/HUS/HUS11.pdf]

9. Opal SM, Girard TD, Ely EW: The immunopathogenesis of sepsis in elderly patients. Clin Infect Dis 2005, 41 Suppl 7:S504-512.

10. Ridda I, Macintyre CR, Lindley R, Gao Z, Sullivan JS, Yuan FF, Mclntyre PB: Immunological responses to pneumococcal vaccine in frail older people. Vaccine 2009, 27:1628-1636.

11. Frasca D, Blomberg BB: Effects of aging on B cell function. Curr Opin Immuno/ 2009, 21:425-430.

12. Arnold CR, Wolf J, Brunner S, Herndler-Brandstetter D, Grubeck-Loebenstein B: Gain and loss of T cell subsets in old age--age-related reshaping of the T cell repertoire. J Clin Immunol 2011, 31:137-146.

13. Krabbe KS, Bruunsgaard H, Qvist J, Hansen CM, Møller K, Fonsmark L, Madsen PL, Kronborg G, Frandsen U, Andersen HØ, Skinhøj P, Pedersen BK: Hypotension during endotoxinemia in aged humans. Eur J Anesthesiol 2001, 18:572-575.

14. Seok J, Warren HS, Cuenca AG, Mindrinos MN, Baker HV, Xu W, Richards DR, McDonald-Smith GP, Gao H, Hennessy L, Finnerty CC, López CM, Honari S, Moore EE, Minei JP, Cuschieri J, Bankey PE, Johnson JL, Sperry J, Nathens AB, Billiar TR, West MA, Jeschke MG, Klein MB, Gamelli RL, Gibran NS, Brownstein BH, Miller-Graziano C, Calvano SE, Mason PH, et al:: Genomic responses in mouse models poorly mimic human inflammatory diseases. Proc Natl Acad SciUSA 2013, 110:5307-3512.

doi:10.1186/cc12754

Cite this article as: Pop-Vicas A, Opal SM: Over-distension of the airways by mechanical ventilation in the elderly: adding insult to injury. Critical Care 2013, 17:165. 